\title{
Sensory Characteristics of Different Types of Chicken
}

\section{Karahi}

Arab Khan Lund ${ }^{1, *}$, Yar Muhammad Jalbani', Abdul Samad Mangsi ${ }^{1}$, Qudratullah Kalwar ${ }^{2}$, Rasool Bux Laghari', Kashif Ali Malik', Muhammad Aqeel Khoso', Abdul Salam Arain ${ }^{1}$

1Department of Animal Products Technology, Shaheed Benazir Bhutto University of Veterinary and Animal Sciences, Sakrand-67210, Sindh, Pakistan

2Department of Animal Reproduction, Shaheed Benazir Bhutto University of Veterinary and Animal Sciences,

Sakrand-67210, Sindh, Pakistan

\section{ABSTRACT}

This study was designed to evaluate the sensory characteristics of different types of chicken karahi, is one of the favorite dishes of Pakistani people. Fifteen trained panelists were asked for the sensory evaluation of karahi. The sensory evaluation showed that the white shahi chicken karahi received significantly $(P<0.05)$ higher score for flavor, tenderness, and overall acceptability $(4.61,4.61, \&$ 7.93 , respectively) than that of koyla chicken karahi $(4.06,3.98 \& 6.66$, respectively) but remained non-significant $(P>0.05)$ with the red shahi chicken karahi $(4.53,4.14 \& 7.33$, respectively). The panel of judges found that the white shahi chicken karahi was tenderer and has improved flavor followed by red shahi chicken karahi in comparison to koyla chicken karahi. However, the panel of judges was found non-significant ( $P>0.05$ ) difference in color and juiciness of white shahi (4.21 \& 4.06, respectively), red shahi (4.29 \& 3.88, respectively) and koyla chicken karahi $(4.55 \& 3.91$, respectively). The koyla chicken karahi received the highest score for color followed by red shahi and white shahi chicken karahi while juiciness was higher in white shahi chicken karahi followed by koyla chicken karahi and red shahi chicken karahi.

It could be concluded that the white shahi chicken karahi received the highest sensory score by the panel of judges followed by red shahi chicken karahi and koyla chicken karahi.

$\begin{array}{ll}\text { Keywords } & \text { *Address of Correspondence } \\ \text { Meat products, sensory properties, } & \text { aarabbaloch@gmail.com }\end{array}$

chicken karahi.

aarabbaloch@gmail.com
Cite this article: Lund AK, Jalbani YM, Mangsi AS, Kalwar Q, Laghari RB, Malik KA, Khoso MA, Arain AS. Sensory Characteristics of Different Types of Chicken Karahi. RADS J. Biol. Res. Appl. Sci. 2019; 10(1): 30-35.

This is an Open Access article distributed under the terms of the Creative Commons Attribution License (http://creativecommons.org/licenses/by/4.0), which permits unrestricted use, distribution, and reproduction in any medium, provided the original work is properly cited.

\section{INTRODUCTION}

Meat is a muscular tissue which is composed of skeletal muscle and connective tissue along with a very small amount of smooth muscles. The meat typically composed of $60-80 \%$ water, $18-20 \%$ proteins, and $0.5-19 \%$ lipids, 1 $1.5 \%$ minerals ${ }^{1}$. Lipid contributes flavour and juiciness of the meat. It may be present in different forms such as marbling and extra muscular fat. The protein content plays an excellent role in the human diet due to the presence of essential amino acids which included methionine, tryptophan, leucine, lysine and threonine ${ }^{2}$.
Based on eating behaviour, human consume meat as well as plants so called omnivorous throughout history. The source of raw meat is by hunting or rearing animals and birds. Livestock and poultry farming give large support to the economy of any country. The consumption of meat in industrial countries is higher, nearly double quantity than the developing countries ${ }^{3}$. The poultry meat production contributes $32.7 \%$ and $1.4 \%$ in the total meat production and GDP, respectively. Its production was 1.39 million 
tons and shares $7.5 \%$ and $12.7 \%$ in agriculture and livestock value added products during 2017-20184.

Chicken meat is one of the most useful diets of human beings due to the economic source of protein ${ }^{5}$. The daily requirement of protein per head is $102.7 \mathrm{~g}$ while its consumption is only $69.61 \mathrm{~g}^{6}$, furthermore, 66 (\%) Pakistanis are deficient in protein due to deficiency of animal protein in diets ${ }^{7}$. The protein requirement gap per head per day is $33.09 \mathrm{~g}$ and the main source of animal origin protein is beef, milk, mutton, poultry meat and eggs $^{8}$. Chicken meat is a common choice of food for people in Pakistan because of the rich source of protein in cheap price in comparison to beef, mutton and chevon'. Chicken meat consumed by manufacturing of various value added products such as tikka, biryani, curry, meat pickle, dry salted meat and karahi10. Among these value added products, the karahi (white, shahi \& koyla) is considered as most common meat product, which is used in daily routines as well as in different events because these can be easily prepared ${ }^{10}$. During the preparation, their physical, chemical and sensory features of meat become changes ${ }^{11}$. Therefore, this study was designed to evaluate the sensory changes and consumer preference to the white shahi, red shahi and koyla chicken karahi.

\section{MATERIALS AND METHODS}

Six kilograms of fresh chicken meat purchased from the commercial market of Sakrand and brought to the Department of Animal Products Technology, Shaheed Benazir Bhutto University of Veterinary and Animal Sciences, Sakrand where all samples were thoroughly mixed and categorized into three parts (2kg/part). Each part of three batches further processed into white shahi, red shahi and koyla chicken karahi as summarized;

\section{White Shahi Chicken Karahi}

The chicken meat $(2 \mathrm{~kg})$ was ground and washed with tap water and transferred to cooking pan then placed on the fire by adding a half litter of cooking oil. The ginger garlic paste (4 tablespoons) was added after five minutes of the cooking. While the black pepper (4 tablespoons), green chili (4 tablespoons) and coriander powder (4 tablespoons) were put after fifteen minutes. After 20 minutes, yoghurt (4 cups) and cream (2 cups) were added, thoroughly mixed and continued to cook further for four to five minutes. Then garam masala (4 tablespoons) and cumin powder ( 3 tablespoons) were added and cooked further for three minutes. White shahi chicken karahi took 30 minutes to be ready ${ }^{12}$.

\section{Red Shahi Chicken Karahi}

The cooking oil ( 1 litter) was put into the cooking pan, placed on the fire, added two chopped onions and cooked until their color changed into brownish then one kilogram of tomatoes were added and cooked for seven minutes. Some green peas and four green chilies were added into the mixture and cooked further three minutes then two kilograms of chicken meat passed through the preliminary process of grinding (grinder) and washing (tape water) were added during the cooking. Then garlic (2 tablespoons), ginger (2 tablespoons), red pepper (3 tablespoons), salt (as per taste), chicken karahi masala (1 pocket), crushed black pepper (1 tablespoon) and few cardamoms were added and further cooked for 15 minutes. Finally added coriander (2 tablespoons) and close the lid and left for three minutes. The red shahi chicken karahi made in 25 minutes $^{13}$.

\section{Koyla Chicken Karahi}

The 2 kilograms of chicken meat ground, washed (tap water), put into the cooking pan, added cooking oil (0.5 liter) and fried on high heat till the color change of chicken. The fried chicken removed and same oil used to fry the garlic paste (1 tablespoons) and ginger paste (1 tablespoons) for developing aroma. After developing aroma, chopped tomatoes $(0.5 \mathrm{~kg})$ were added and fried at high heat for ten minutes then added turmeric powder ( 0.5 tablespoon), salt (as per taste), water (half cup) and the fried chicken and cooked at medium flame for 15 minutes. Then flame increased high in order to fry the chicken and added crushed black pepper (1 tablespoons), karahi masala (half pocket), garam masala (1 tablespoons) and cooked further two minutes. After two minutes, lemon juice (1 tablespoon), green chilies (few pieces) were added and finally smoking flavor was developed by coal smoking for five minutes. Koyla chicken karahi prepared in 35 minutes $^{14}$. 


\section{Sensory Analysis}

Three products i.e. white shahi, red shahi and koyla chicken karahi were evaluated by the panel of judges after 30 minutes of cooking for sensory evaluation. Fifteen panelists (of different sex and age) were selected from teaching staff (08) and final year students (07). The panel of judges was instructed regarding color, tenderness, juiciness, flavor and overall acceptability of meat products. The six point hedonic scale (one extremely undesirable \& six extremely desirable) was used for color, tenderness, juiciness and flavor ${ }^{15}$ while nine hedonic scale was used for overall acceptability where nine means like extremely and one means dislike extremely ${ }^{16}$.

\section{Statistical Analysis}

The sensory evaluation data was collected and analysed by using Statistix SXW (Version 8.1 copyright 2005, Analytical software, USA). Furthermore, the significant variation was found by using analysis of variance and least significant difference functions of the Statistix SXW17.

\section{RESULTS AND DISCUSSIONS}

\section{Colour}

The colour scores for white shahi, red shahi and koyla chicken karahi are presented in Figure 1. The values show the non-significant $(P>0.05)$ difference among three meat products. All three types of karahi scored in the range of moderately desirable to very desirable for their colour by the panel of judges. According to the panel of judges, the colour of three products was remain attractive however, the colour of koyla chicken karahi was a little bit more rated by panel of judges. The scores are well supported by the results of Maya and Abdullah, ${ }^{16}$ where panels also unable to differentiate the colour of different meat products. The difference was non-significant $(P>0.05)$ among the various beef products. Alamin et al., ${ }^{18}$ also conducted the research for the sensory characteristics of different sausage products where they found the non-significant $(P>0.05)$ difference for colour among various types of sausages.

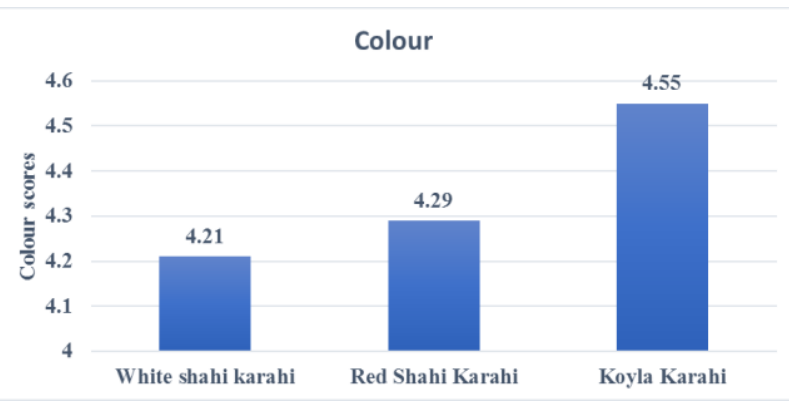

SE $\pm=0.303$

$\operatorname{LSD}(0.05)=$ Non-significant

Figure 1. Colour scores for different chicken meat products.

\section{Flavor}

The flavour of the value added meat products are shown in Figure 2. The scores for flavour were significantly different $(P<0.05)$ in between white shahi and koyla chicken karahi while variation was non-significant $(P>0.05)$ in between white shahi and red shahi chicken karahi as well as in red shahi and koyla chiken karahi. The white shahi chicken karahi received the highest scores for flavour followed by red shahi and koyla chicken karahi. It is found that the flavour produced by smoke in koyla chicken karahi was not attractive in comparison to flavour developed by addition of youghurt in white shahi chicken karahi which was preferred by the panel of judges. The results are not in agreement to the findings of Simon, ${ }^{19}$ where the panel of judges found non-significant $(P>0.05)$ different for flavour among different beef products added with different concentrations of the preservatives. Khatami, ${ }^{20}$ and Shalash, ${ }^{21}$ also found a similar flavour and taste, respectively in the different camel meat products. This significant difference $(P<0.05)$ among flavour of different chicken products because of the different source of flavour was used such as yoghurt used in white shahi chicken and smoke in koyla chicken karahi. Furthermore, present findings are in line with the findings of Alamin, ${ }^{15}$ who reported that the panel of judges found a significant difference $(P<0.05)$ among different types of red meat. These results are also agreed with the results of $1,22,23$ where panelists found significant variation among different meat products. 


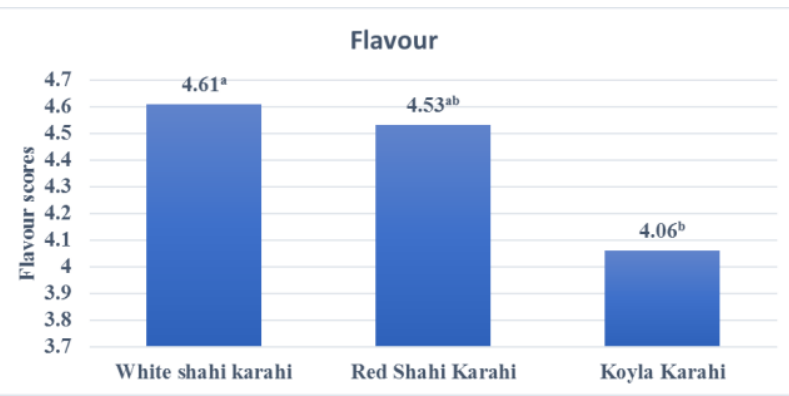

$\operatorname{LSD}(0.05)=0.526$

SE $\pm=0.261$

Figure 2. Flavour scores for different chicken meat products.

\section{Juiciness}

As presented in Figure 3, the juiciness scores for different karahi were not significantly $(P>0.05)$ different. The Panel of judges scored as moderately unjuicy to moderately juicy for different meat products. The white shahi chicken karahi was scored for highest juiciness followed by koyla and red shahi chicken karahi. This non-significant variation might be due to addition of yoghurt which were not added to both red shahi and koyla chicken karahi. James and Berry ${ }^{24}$ reported that judges for sensory evaluation were found the non-significant difference in the different meat products. These results are also supported by the findings of Maya and Abdullah, ${ }^{16}$ who reported that trained judges were unable to find a significant difference in the juiciness of different meat products.

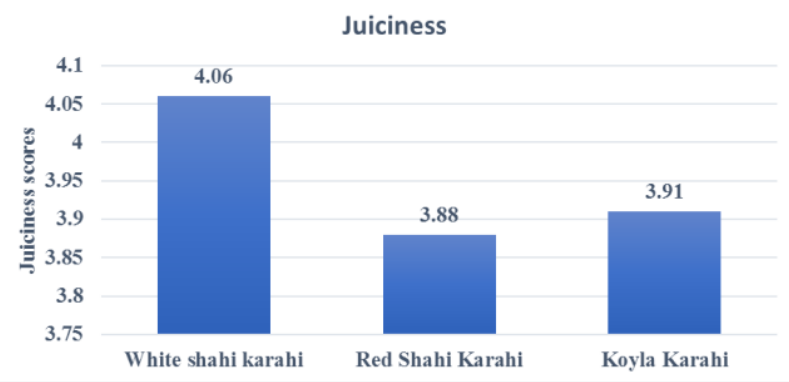

SE $\pm=0.368$

$\operatorname{LSD}(0.05)=$ Non-significant

Figure 3. Juiciness scores for different chicken meat products.

\section{Tenderness}

The tenderness of white and red shahi chicken karahi was moderately desirable while the tenderness of koyla chicken karahi was moderately undesirable (Figure 4).
The panel of judges preferred the white shahi chicken karahi followed by red shahi chicken karahi than that of koyla chicken karahi. Statistically, the white shahi chicken karahi significantly $(P<0.05)$ different than that of koyla chicken karahi while non-significantly $(P>0.05)$ from red shahi chicken karahi. Similarly, the trained judges unable to differentiate the red shahi and koyla chicken karahi. The present results show disagreement with the findings of Alamin et al., ${ }^{18}$ they reported similar tenderness in different types of sausages. It also disagrees with the sensory evaluation of Alamin, ${ }^{15}$ and Maya \& Abdullah, ${ }^{16}$ of different types of red meat and packaged roast beef, respectively where panelists could not differentiate the tenderness. The reason behind the significant difference is the use of youghurt as white shahi chicken karahi was only meat products that significantly varied while there was non-significant variation in between red shahi and koyla chicken karahi. Kadim et al.,25 reported that the panel of judges found a significant difference between different meats. Cassens et al., ${ }^{26}$ also reported that the significant variation in the tenderness which supports the present findings. Moreover, Cavestany et al., ${ }^{27}$ reported many factors which affect the tenderness of the meat products such as product formulation, fat and protein content and other factors.

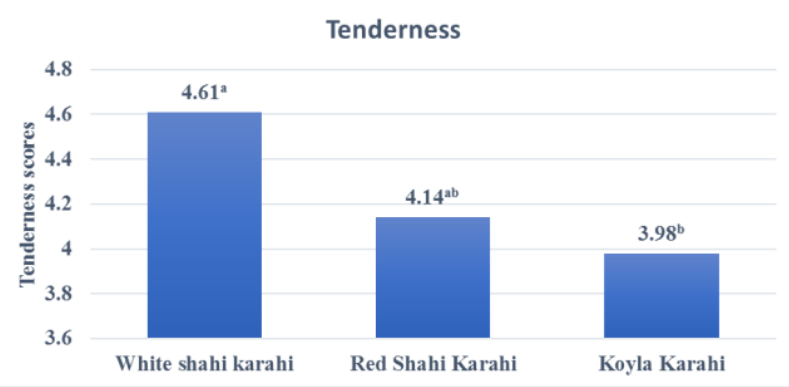

$\operatorname{LSD}(0.05)=0.625$

SE $\pm=0.309$

Figure 4. Tenderness scores for different chicken meat products.

\section{Overall Acceptability}

The overall acceptability depends on the scores of all sensory parameters, therefore, a product which had received high sensory evaluation scores regarding colour, flavour, juiciness, and tenderness ultimately high in overall acceptability. The hedonic nine scales for overall acceptability showed significant $(P<0.05)$ difference in 
between white shahi and koyla chicken karahi however variation was not significantly different in between white and red shahi chicken karahi (Figure 5). The panel of judges scored at the range of 'like moderately to like very much' for white and red chicken shahi karahi while at the range of 'like slightly to like moderately for koyla chicken karahi. The overall acceptability scores for different karahi disagreed with the sensory evaluation of Maya and Abdullah, ${ }^{16}$ who reported that the panel of judges found similar overall acceptability in different types of roast beef. However, the results are well supported by findings of Babiker and Tibin ${ }^{28}$ who found the significant difference in the overall acceptability of sausages prepared by different animal meat. It also matches with findings of Alamin, ${ }^{15}$ and Alamin et al., ${ }^{18}$ who found the significant variation in between different types of red meat products and sausages, respectively.

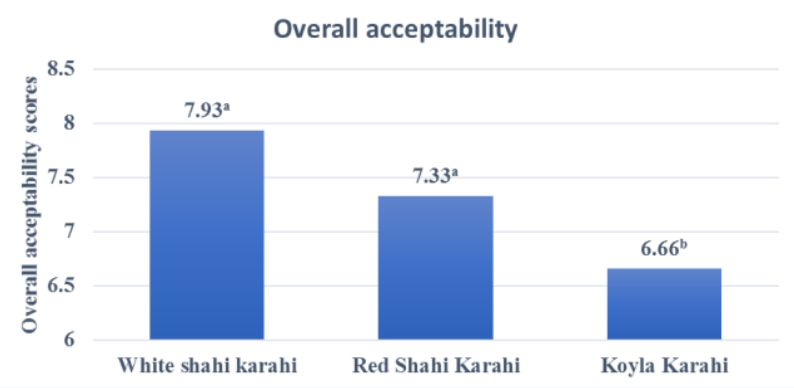

$\operatorname{LSD}(\mathbf{0 . 0 5})=0.659$

SE $\pm=0.326$

Figure 5. Overall acceptability scores for different chicken meat products.

\section{CONCLUSIONS}

The sensory evaluation of different chicken karahi revealed that the white shahi chicken karahi highly preferred by a trained panel of judges regarding flavor, juiciness, tenderness and overall acceptability. This indicates that the yoghurt added in white shahi karahi changes the sensory characteristics of the products in which it added.

\section{REFERENCES}

1. Jimenez-Colmenero F, Pintado T, Cofrades S, RuizCapillas C, Bastida S. Production variations of nutritional composition of commercial meat products. Food Res Int 2010; 43(10):2378-84.
2. Varnam A, Sutherland JM, Sutherland JP. Meat and meat products: technology, chemistry and microbiology. Springer Science \& Business Media; 1995.

3. Kristensen L, Støier S, Würtz J, Hinrichsen L. Trends in meat science and technology: The future looks bright, but the journey will be long. Meat science. 2014; 98(3):322-9.

4. Economic Survey of Pakistan. Ministry of Food, Agriculture and Livestock, Government of Pakistan, Finance Division (Livestock Wing), Islamabad. 201718.

5. Qureshi MS. Annual Progress Report. 1989-90. Poultry Development Center (PRI), Rawalpindi, Punjab: 1990. p. 295.

6. Economic Survey of Pakistan. Ministry of Food, Agriculture and Livestock, Government of Pakistan, Finance Division (Livestock Wing), Islamabad. 2003.

7. Maqbool A. Marketing of commercial poultry, poultry meat and eggs in Faisalabad City (Doctoral dissertation, M. Sc. Thesis University of Agriculture Faisalabad, Pakistan). 2002.

8. Economic Survey of Pakistan. Ministry of Finance, Planning and Development, Islamabad. 2002-03.

9. Assis K, Komilus CF, Bonaventure B, Mohd Shahrol Ridzal O. Consumption Patterns of Chicken, Beef and Mutton: A Study among Consumers in Kota Kinabalu, Sabah, Malaysia. Global Journal of Advanced Research. 2015;2:279-86.

10. Dikeman M, Devine C. Encyclopedia of meat sciences: 3-volume set. Academic Press, London. 2014.

11. Townsend WE, Ackerman SA, Witnauer LP, Palm WE, Swift CE. Effects of types and levels of fat and rates and temperatures of comminution on the processing and characteristics of frankfurters. J Food Sci. 1971;36(2):261-5.

12. Sooperchef. Chicken White Karahi Recipe. [cited 2017]. Available from: https://www.sooperchef.pk/chicken-white-karahirecipe/

13. Qureshi Zakir Chef. Chicken Karahi Recipe. [cited 2019]. Available from: http://www.khanapakana.com/recipe/0a6d06d8-071f49b6-a46c-bfb789687d4d/chicken-karahi

14. Diya Ansari. Koyla Chicken Karahi Recipe. [cited 2017]. Available from: https://www.therecipespk.com/koyla-karahi-recipe/

15. Alamin SA. Sensory Evaluations of Different Types of Red meat in Sudan. Bull Env Pharmacol Life Sci. 2015;4:45-8.

16. Maaya T, Al-Abdullah BM. Sensory Evaluation of Different Packaged Roast Beef Treatments Designed 
for the Extension of Its Shelf Life. Food and Nutrition. 2016;7:1052-61.

17. Steel RGD, Torrie JH, Dickey DA. Principles and procedures of statistics: a biometrical approach. Third Edition. New York: McGraw-Hill; 1997.

18. Alamin SA, Ahmed DA, Agab H. A Study of Sensory Evaluations of Different Types of Sausages in the Sudanese Palate. International Journal of Research. 2015;14.

19. Simon S, Ellis DE, MacDonald BD, Miller DG, Waldman RC, Westerberg DO. Influence of nitrite and nitrate curing ingredients on quality of packaged frankfurters. J Food Sci. 1973;38(6):919-20.

20. Khatami K. Camel meat: A new promising approach to the solution of meat and protein in the arid and semi-arid countries of the world. Ministry of Agriculture, Tehran. 1970.

21. Shalash MR. The production and utilization of camel meat. In International Foundation for science (IFS), International Symposium on camels. Sudan. 1979. p. 231-47.
22. Babiker SA, Yousif OK. Chemical composition and quality of camel meat. Meat science. 1990;27(4):2837.

23. Schönfeldt HC, Naude RT, Bok W, Van Heerden SM, Sowden L, Boshoff E. Cooking-and juiciness-related quality characteristics of goat and sheep meat. Meat Science. 1993;34(3):381-94.

24. James NA, Berry BW. Use of chevon in the development of low-fat meat products. Journal of animal science. 1997;75(2):571-7.

25. Kadim IT, Mahgoub O, Purchas RW. A review of the growth, and of the carcass and meat quality characteristics of the one-humped camel (Camelus dromedaries). Meat Science. 2008;80(3):555-69.

26. Cassens, RG. Residual nitrite in cured meat. Food technology (USA).1997.

27. Cavestany M, Colmenero FJ, Solas MT, Carballo J. Incorporation of sardine surimi in bologna sausage containing different fat levels. Meat science. 1994;38(1):27-37.

28. Babiker SA, Tibin IM. Camel research paper from Sudan. Addis Ababa, Ethiopia: ILCA.1986. 